\title{
Surface Area Analysis in Edentulous Jaws of Patients with Skeletal Class I
}

\author{
Srdjan D. Poštić \\ Clinic of Dental Prosthetics, School of Dentistry, University of Belgrade, Belgrade, Serbia
}

\begin{abstract}
SUMMARY
Introduction The surface area of edentulous jaw has been considered as an important functional and anthropometric parameter. The aim of this study was to assess the surface area of supporting tissue in edentulous jaws of patients with the skeletal class I.

Material and Methods Thin aluminum foils ( $0.5 \mathrm{~mm}$ of thickness) were adapted on plaster surfaces of 139 pairs of edentulous jaws casts. Foils were positioned on a millimeter-paper in order to measure their areas. Additionally, surface areas were measured using a mechanic plan-meter (G. Coradi, Zurich, Switzerland, serial no. 49823). The measurement error was $1 \%$. Skeletal class of edentulous jaws was determined by analysis of lateral cephalometric radiographs, and assessing the ANB (SNA, SNB) angle.

Results The average surface area of edentulous upper jaws was $4654 \pm 407 \mathrm{~mm}^{2}$ in males, and $4212 \pm 368 \mathrm{~mm}^{2}$ in females. Edentulous lower jaws had average surface area of $2843 \pm 339 \mathrm{~mm}^{2}$ in males, and $2334 \pm 295 \mathrm{~mm}^{2}$ in females. Statistically significant difference $(p<0.001)$ was found in comparison of surface areas and dimensions of upper and lower edentulous jaws in male and female. ANB values ranged from 2 to 4 degrees.

Conclusion The surface area is an important parameter in the analysis of edentulous jaws. Edentulous jaws in males had greater surface areas and dimensions as compared to females. Edentulous areas on the right side were not absolutely symmetric to areas on the left side.
\end{abstract}

Keywords: edentulous; bone; mandible; maxilla

\section{INTRODUCTION}

The surface area of edentulous jaw is an important functional and anthropometric parameter. It can be analyzed directly in mouth, on jaw impressions, as well as on casts. The analysis of master cast provides valuable information about the surface area in edentulous jaws. However, preliminary-study cast made of "soft" alabaster dental plaster is usually utilized for this purpose [1-5].

The surface area of edentulous jaws has not been extensively studied by recent studies.

During the assessment of maxillo-mandibular jaw relationships an inevitable and important step is to determine skeletal relations of upper and lower jaws in one of the following: skeletal class I (neutrorelation), skeletal class II - distal (retrognathic) or skeletal class III (prognathic) relation $[6,7,8]$.

The aim of this study was to assess the surface area of supporting tissue in edentulous jaws of patients with the skeletal class I.

\section{MATERIAL AND METHODS}

One hundred and thirty nine pairs of casts - the total of 278 diagnostic preliminary study casts of edentulous upper and lower jaws were analyzed. Casts were produced using plaster (Galiplaster-type 2, Galenika) and stone (Gipsogaltype 3, Galenika) in equal proportion (relation of powder of gypsum-water 0.5:0.5:1 (1 part of water)), after taking preliminary impression of edentulous jaws using alginate (Alginogal, Galenika, Serbia) in standard metal tray (Figures 1a and 1b).

Aluminum foils ( $0.5 \mathrm{~mm}$ thick) were adapted (Figures $1 \mathrm{c}$ and 1d) on the surface of 139 pairs of casts of edentulous upper and lower jaws. The edges of foils were traced on millimeter metric paper in order to measure surface areas (Figures $2 \mathrm{a}$ and $2 \mathrm{~b}$ ). The surface within traced borders was calculated for each foil (Figures $3 a$ and $3 b$ ).

An additional measurement of surface areas was performed using a mechanic plane-meter (G. Coradi, Zurich, Switzerland, serial no. 49823) (Figure 4). The error of measurement was $1 \%$. Skeletal class of edentulous patients was determined using lateral cephalometric profile radiographs, by analysis of ANB (SNA, SNB) angle (Figures 5 and 6).

\section{RESULTS}

The values of surface area in edentulous upper jaws were $4654 \pm 407 \mathrm{~mm}^{2}$ in male and $4212 \pm 368 \mathrm{~mm}^{2}$ in female patients (Figure 7 ). The difference was statistically significant $(\mathrm{p}<0.001)$. The values of surface area in edentulous 

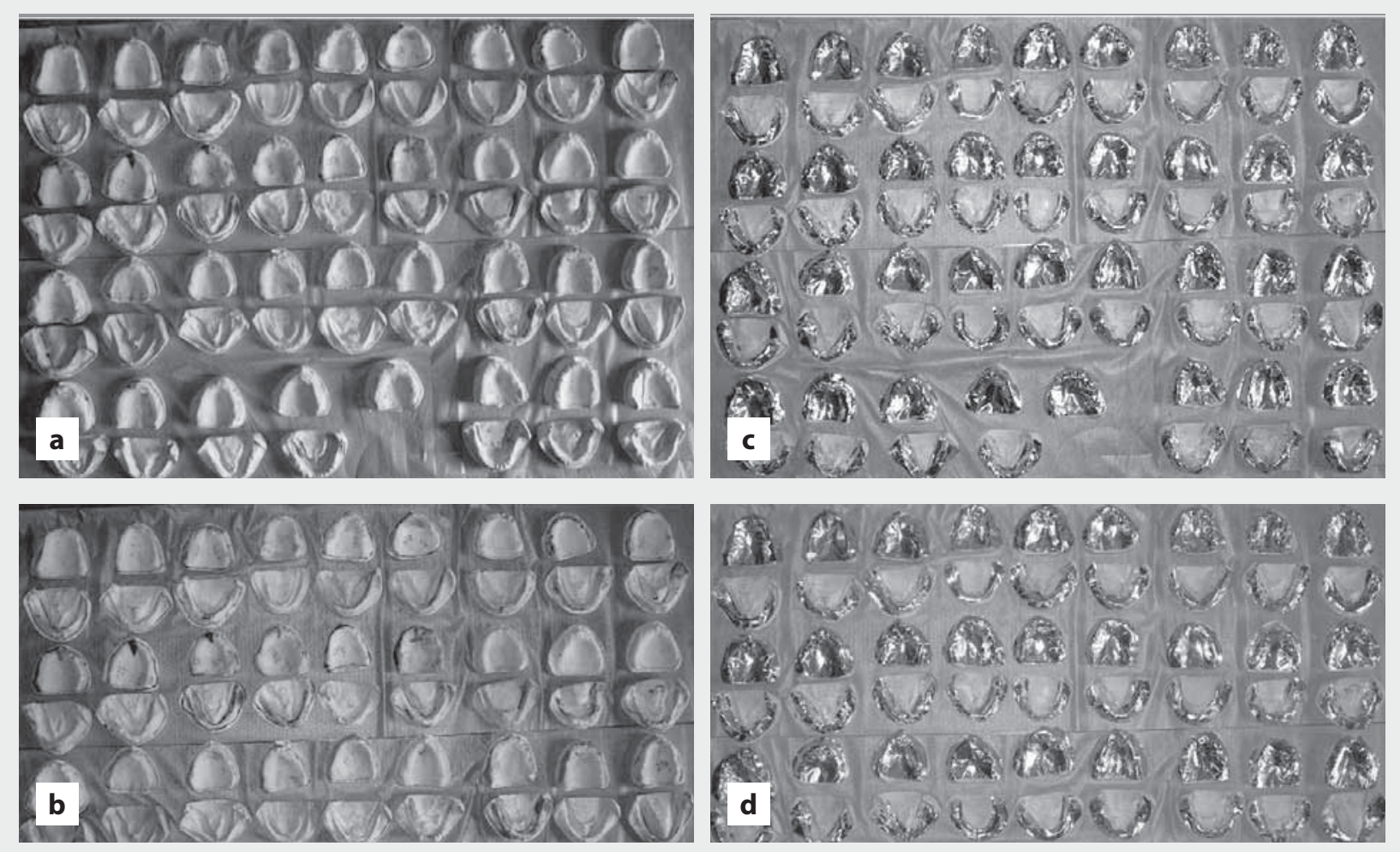

Figure 1. a) Assessed diagnostic-preliminary casts of edentulous jaws; b) Assessed casts of edentulous upper and lower jaws; c, d) Aluminum foils positioned onto investigated casts

Slika 1. a) Ispitivani anatomski modeli bezubih vilica; b) Ispitivani modeli bezubih gornjih i donjih vilica; c, d) Aluminijumske folije postavljene na ispitivane modele od gipsa

lower jaws were $2843 \pm 339 \mathrm{~mm}^{2}$ in males and $2334 \pm 295$ $\mathrm{mm}^{2}$ in females (Figure 8). The difference was also statistically significant $(\mathrm{p}<0.001)$. Statistically significant difference $(\mathrm{p}<0.001)$ was calculated for the comparison of surface areas of edentulous upper and lower jaws. The values of ANB angles amounted from 2 to 4 degrees.

\section{DISCUSSION}

Preliminary diagnostic study casts of edentulous upper and lower jaws are mandatory but also the most common way to do the analysis, make diagnosis and therapy plan for

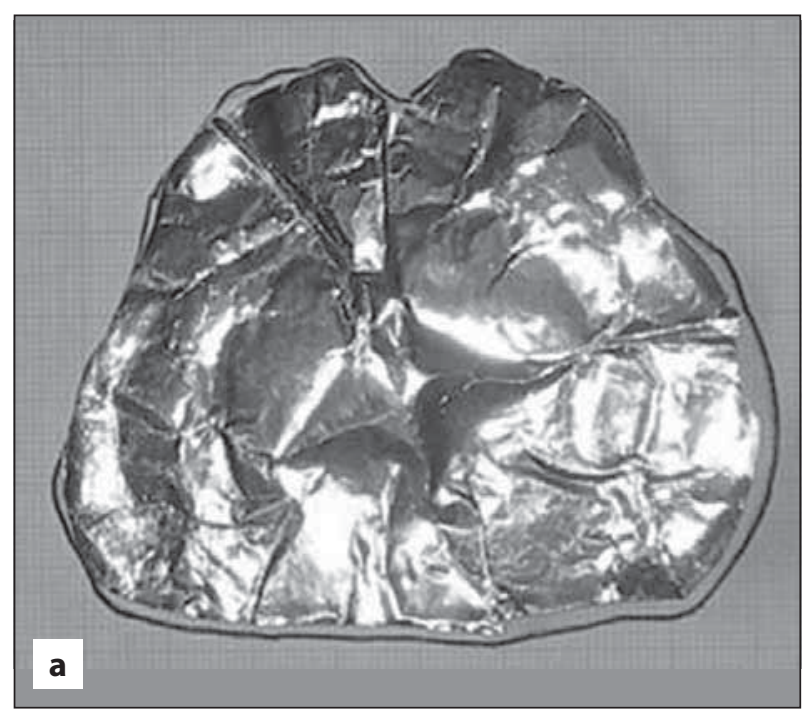

complete dentures [1-5]. They can be used in analysis of shape, dimensions and surface area of supporting tissues in edentulous jaws prior to making complete dentures, as well as in subsequent clinical and laboratory steps during fabrication of complete dentures. Also, preliminary casts can be useful in analysis of edentulous jaws prior to implant positioning as well as in preprosthetic surgery to evaluate edentulous ridges and amount of needed adjustment in order to achieve successful positioning and stability of dentures $[10,11]$.

Limited amount of data about the surface area of edentulous jaws has been found in dental literature regardless the fact that surface area is of great importance not just

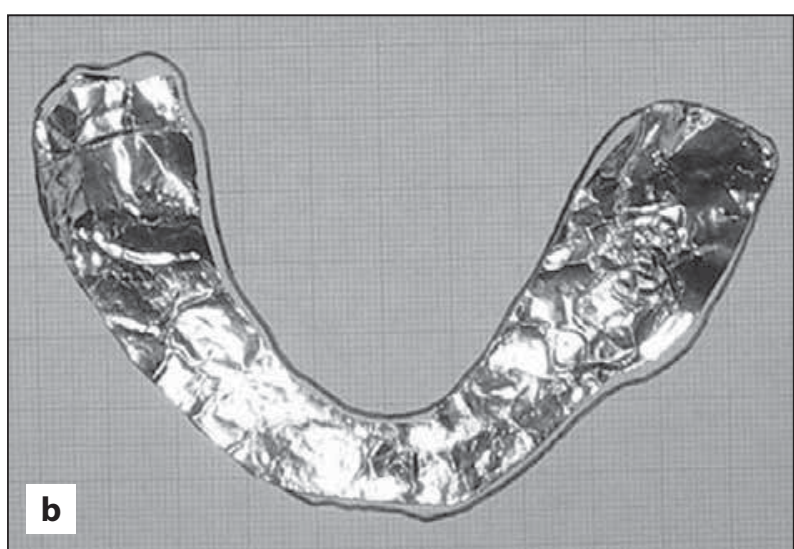

Figure 2. Aluminum foil transferred from a cast and placed on millimeter paper: edentulous maxilla (a) and edentulous mandible (b) Slika 2. Aluminijumska folija preneta sa modela i postavljena na milimetarsku hartiju: bezuba gornja vilica (a) i bezuba donja vilica (b) 

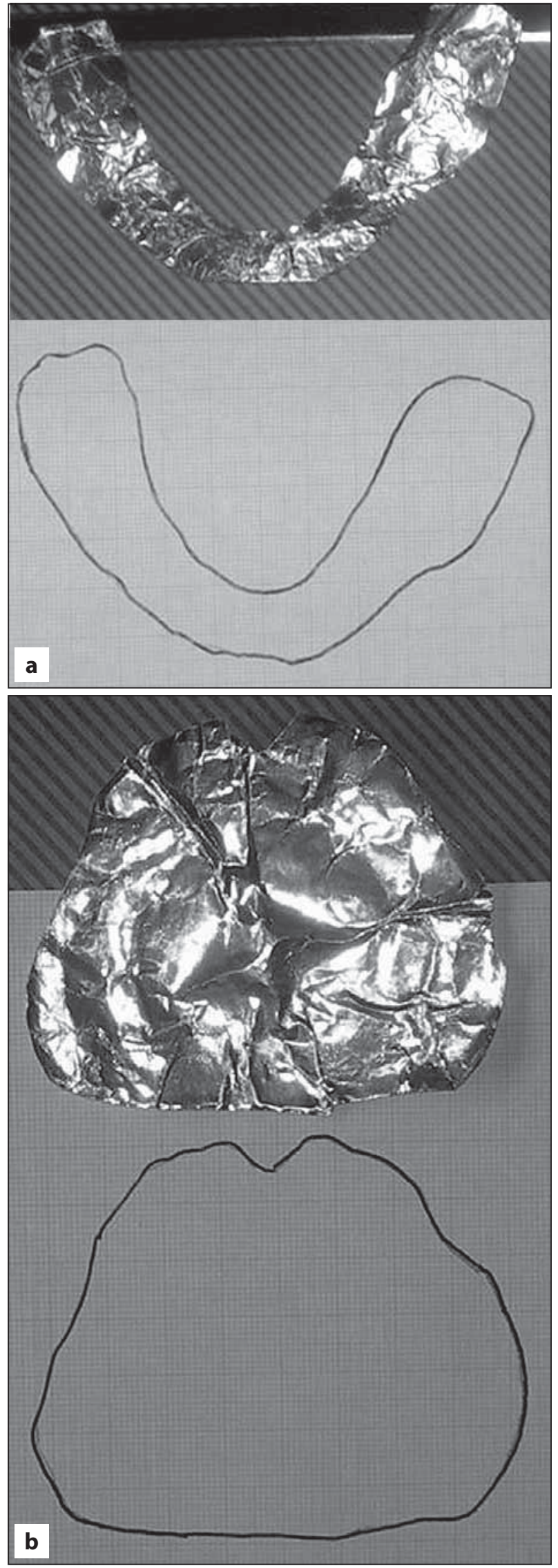

Figure 3. Aluminum foil transferred from a cast and borders of determined surface traced on millimeter paper: edentulous mandible (a) and edentulous maxilla (b)

Slika 3. Aluminijumska folija sa modela i granice označene površine na milimetarskom papiru: bezuba donja vilica (a) i bezuba gornja vilica (b) in relation to better retention and stability of dentures but also in treatment planning of pre-prosthetic and reconstructive surgery. Up to date, several methods of measuring surface areas in edentulous jaws have been described: the method of replication with application of an empiric formula, the measurement of surface area using polar

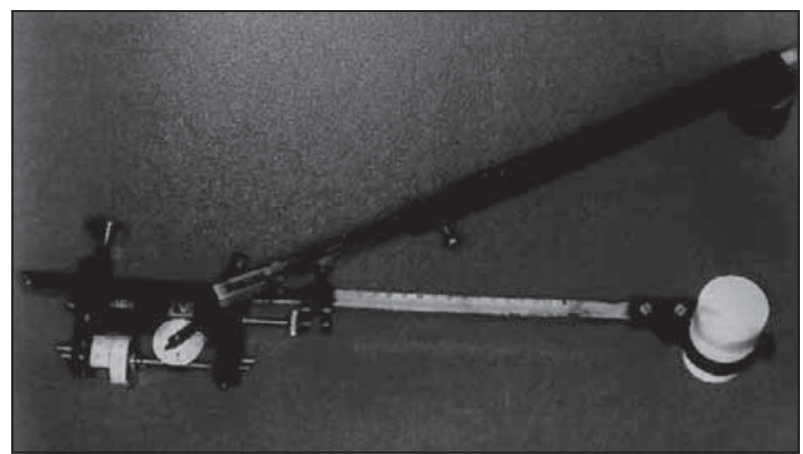

Figure 4. Plan-meter

Slika 4. Planimetar

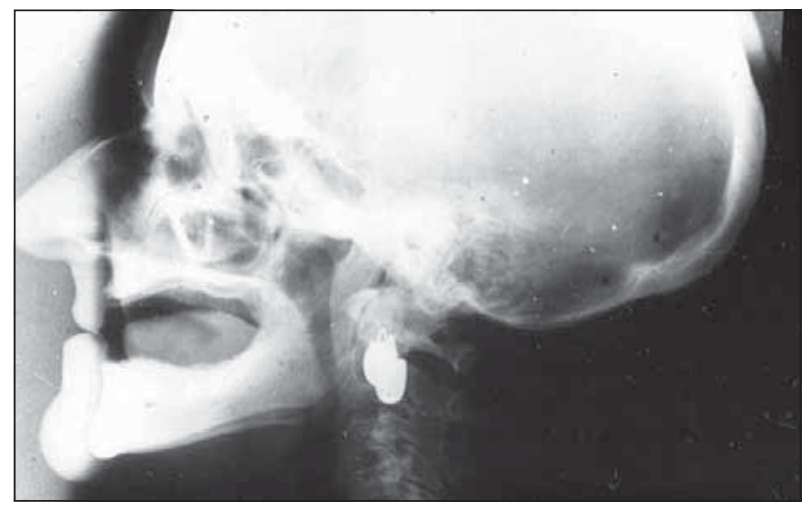

Figure 5. Profile cephalometric radiograph of an edentulous women patient with skeletal class I

Slika 5. Proflini telerendgenski radiogram pacijentkinje bez zuba sa skeletnom klasom I

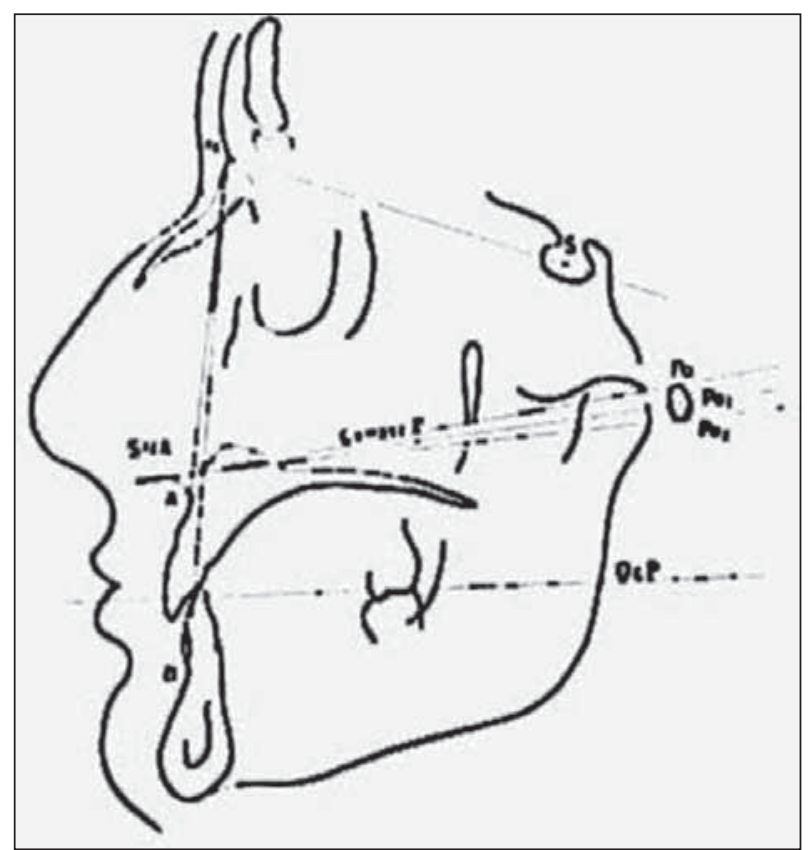

Figure 6. Schematic representation of ANB angle on profile radiograph

Slika 6. Shema označavanja ugla ANB na profilnom radiogramu 


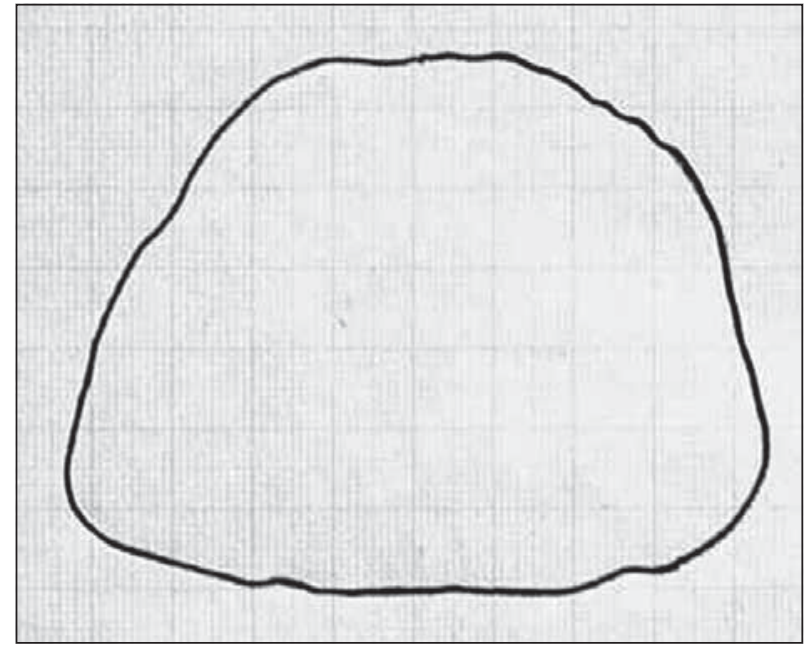

Figure 7. Borders of surface area of an edentulous maxilla traced on millimeter paper

Slika 7. Granice površine bezube gornje vilice na milimetarskom papiru

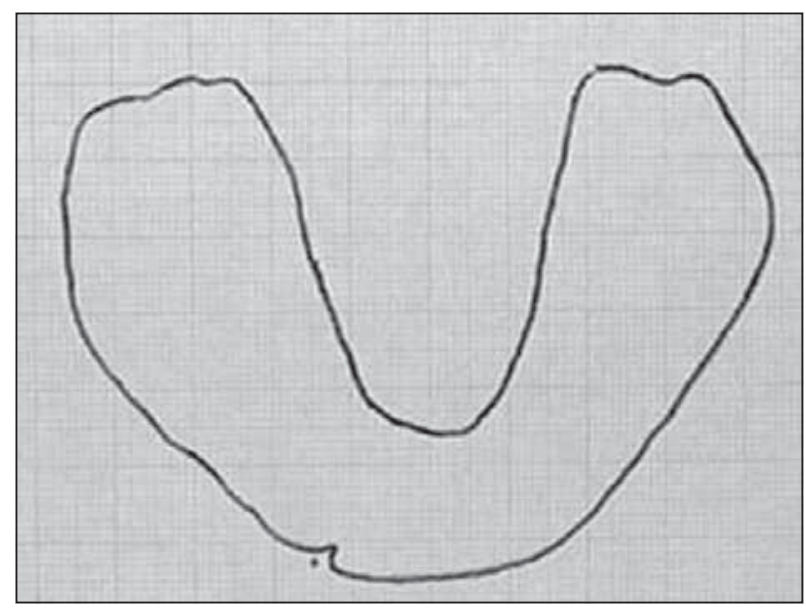

Figure 8. Borders of surface area of an edentulous mandible traced on millimeter paper

Slika 8. Granice površine bezube donje vilice na milimetarskom papiru

plane-meter, three-dimensional finite element analysis of load transmission in edentulous jaws, and 3-D virtual model of jaws with possibility for analysis of determined surface of edentulous jaws [12-15]. The method of using plane-meter can be considered as one of the simplest and widely acceptable method in everyday dental practice. It should be emphasized that this method has good precision and almost insignificant error of measurement $[13,16]$.

Beside the assessment of shape, dimensions, surface and configuration of supporting tissues, a preliminary study cast gives information about the surface area which will be loaded by denture base. The surface area of supporting tissues indicates two important factors: whether and how intensively the reduction of supporting tissue is present in the mouth, and the extent of remaining surface that could be loaded with denture's base. Considering the fact that complete denture represents rigid form which is aligned onto bearing surface, the extent of a denture base is important factor for denture stability. Basically, if the surface to which a denture will be aligned has greater surface area, the denture will be more stable. On the contrary, if the surface area loaded with a denture is smaller, the denture will not be stable. Therefore, the assessment of real dimensions of supporting surface area is important parameter when assessing conditions of supporting tissues $[6,9,11,16]$.

Skeletal jaw relationship is determined and constant parameter which remains even after extractions of all teeth $[6,7,8]$. Concerning this, it is very important to understand skeletal jaw relationship in edentulous patients to avoid that eventual discrepancies and differences in dimensions of jaws are attributed to the process of resorption. In these cases, reduced dimensions of mandible could be considered by mistake as skeletal class II, or enlarged dimensions of mandible as skeletal class III [6]. In this study, only patients with skeletal class I were assessed. Regardless the fact that in this study some reductions of jaws were recorded as consequence of edentulous ridge resorption, it could be advocated that the relation of maxilla and mandible remained skeletal class I (taking into consideration small discrepancies and deviations).

On which cast the analysis of surface should be done? It was known from everyday dental practice that edentulous jaws casts can be obtained using preliminary alginate impression in standard metal tray, or functional impression using zinc-oxide-eugenol in custom tray $[1-5,10]$. So, should analysis be done on the surface of master cast made of stone, or on diagnostic preliminary cast made of plaster? Considering the fact that master cast will show anatomic structures as well as borders between mobile and immobile mucosa more reliably, it seems that analysis should be done on master cast made of stone. However, since reproduction of supporting tissue is satisfactory and borders between mobile and immobile mucosa are clearly recognized even on diagnostic cast, the analysis of surface can be successfully performed on diagnostic (preliminary) cast as shown in this study. In addition, the analysis of diagnostic cast is routinely used procedure at the beginning of pre-prosthetic reconstructive surgical treatment of edentulous jaws.

\section{CONCLUSION}

Surface area is an important parameter in the analysis and assessment of supporting tissues in edentulous jaws. Supporting areas of edentulous jaws were greater in male than in female patients. Edentulous areas on the right side were not absolutely symmetric when compared to the relevant areas on the left side.

\section{NOTE}

This study was presented on The $50^{\text {th }}$ International Congress of Anthropologic Society of Serbia, which was held in Jagodina, June 1-4, 2011. 


\section{REFERENCES}

1. Trifunović DM, Radlović S, Kandić M, Nastić M, Petrović A, Krstić $M$, et al. Stomatološka protetika - pretklinika. Beograd: Zavod za udžbenike i nastavna sredstva; 1995.

2. Zarb GA, Bolender CL, Eckert SE, Fenton AH, Jacob RF, MericskeStern R. Prosthodontic Treatment for Edentulous Patient. 12th ed. St Louis: Mosby; 2004

3. Basker RM, Davenport JC. Prosthetic Treatment of the Edentulous Patients. 4th ed. Munksgaard: Blackwell; 2002.

4. Biesaga RK. Protetyka stomatologiczna w teorii i praktyce. Lodz: Wydawnictwo BESTOM-Dentonet; 2005.

5. MacEntee MI. The complete denture - a clinical pathway. Chicago: Quintessence Publ. Co; 1999.

6. Krstić M, Petrović A, Stanišić-Sinobad D, Stošić Z. Totalna proteza. Gornji Milanovac: Dečje novine; 1991.

7. Sinobad D, Poštić SD. Roentgencraniometric indicators of the position of the occlusal plane in natural and artificial dentitions. Eur J Prosthodont. 1996; 4:169-74.

8. Sinobad-Stanišić D, Poštić SD, Popović VM. Disconcordance of skeletal and skin points in prosthetic plane determination. J Dent Res. 1999; 78:145.

9. Poštić SD. Preventivna uloga totalnih proteza. XXIII simpozijum zdravstveno vaspitanje u stomatologiji, jun, Zaječar, 2007. Zbornik referata i radova XXIII, XXIV i XXV simpozijuma zdravstvenog vaspitanja u stomatologiji. Stomatološki glasnik Srbije. 2009; 56:42.
10. Chee W, Jivraj S. Treatment planning of the edentulous mandible. Br Dent J. 2006; 201:337-47.

11. Cawood II, Howell RA. Reconstructive preprosthetic surgery: I. Anatomical considerations. Int J Oral Maxillofac Surg. 1991; 20:75-82.

12. Mohammed H, Johnston WM, O'Brien WJ. Empirical equation for estimating the area of a maxillary edentulous jaw. I Dent Res. 1973; 52:725-30.

13. Koçi N, Koçi B. The measurement of the surface area of the complete denture by means of the polar planimeter. Balkan Journal of Stomatology. 2002; 6:178-81.

14. Bevilacqua M, Tealdo T, Pera F, Menini M, Mossolov A, Drago C, et al. Three-dimensional finite element analysis of load transmission using different implant inclinations and cantilever lengths. Int J Prosthodont. 2008; 21:539-42.

15. Lu Y, Lou H, Rong Q, Dong J, Xu J. Stress area of the mandibular alveolar mucosa under complete denture with linear occlusion at lateral excursion. Chin Med J. 2010; 123:917-21.

16. Poštić S. Analiza žvaćnih ciklusa registrovanih elektrognatografskom metodom [magistarski rad]. Beograd: Stomatološki fakultet Univerziteta u Beogradu; 1991.

Received: 05/09/2011 • Accepted: 15/11/2011 


\title{
Analiza površina bezubih vilica na modelima od gipsa kod pacijenata sa skeletnom klasom I
}

\author{
Srđan D. Poštić \\ Klinika za stomatološku protetiku, Stomatološki fakultet, Univerzitet u Beogradu, Beograd, Srbija
}

\begin{abstract}
KRATAK SADRŽAJ
Uvod Površina bezube vilice je važan funkcionalni i antropometrijski parametar. Cilj rada je bio da se ispitaju i izmere površine nosećih tkiva bezubih vilica pacijenata sa skeletnom klasom I.

Materijal i metode rada Uz površine gipsa na 139 parova preliminarnih anatomskih modela bezubih gornjih i donjih vilica adaptirane su aluminijumske folije (debljine $0,5 \mathrm{~mm}$ ), a zatim postavljene na milimetarsku hartiju radi merenja površina. Sekundarno, zbog provere, površine su izmerene i pomoću mehaničkog planimetra (G. Coradi, Zürich, Switzerland, serial no. 49823). Greška pri merenju je iznosila 1\%. Skeletna klasa bezubih vilica je utvrđena na osnovu profilnih telerendgenskih radiograma glave i analize ugla ANB (SNA-SNB).

Rezultati Površine bezubih gornjih vilica su bile $4654 \pm 407 \mathrm{~mm}^{2}$ kod muškaraca i $4212 \pm 368 \mathrm{~mm}^{2}$ kod žena, a površine bezubih donjih vilica $2843 \pm 339 \mathrm{~mm}^{2}$ kod muškaraca i $2334 \pm 295 \mathrm{~mm}^{2}$ kod žena. Utvrđena je statistički značajna razlika $(p<0,001)$ između površina i veličina donjih i gornjih bezubih vilica. Izmerene vrednosti uglova ANB bile su 2-4 stepena.

Zaključak Površina je važan parametar u analizi i proceni nosećih tkiva bezube vilice. Izmerene površine bezubih gornjih vilica su veće kod muškaraca nego kod žena. Bezube površine na desnoj strani nisu potpuno simetrične bezubim površinama na levoj strani.
\end{abstract}

Ključne reči: bezubost; kost; mandibula; maksila

\section{UVOD}

Površina bezube vilice je važan funkcionalni i antropometrijski parametar. Ona se može analizirati u ustima, na osnovu otiska vilice ili na modelima vilica od gipsa. Najveće mogućnosti u pogledu sagledavanja i premeravanja površine bezube vilice pruža analiza na radnim modelima od gipsa. Najčešće se primenjuje analiza na studijskim, anatomskim modelima izrađenim od mekog „alabaster” gipsa [1-5].

$\mathrm{U}$ dosadašnjim istraživanjima površina bezube vilice se retko ispitivala.

U proceni međusobnog odnosa bezubih vilica nezaobilazan i važan postupak je određivanje skeletnih odnosa vilica bezubih pacijenata. Skeletni odnos bezubih vilica može pripadati prvoj (neutroodnos), drugoj (retrognatija) ili trećoj (prognatija) skeletnoj klasi $[6,7,8]$.

Cilj rada bio je da se ispitaju i izmere površine nosećih tkiva bezubih vilica pacijenata sa skeletnom klasom I.

\section{MATERIJAL I METODE RADA}

U radu je ispitano 139 parova vilica, odnosno 278 preliminarnih anatomskih modela bezubih gornjih i donjih vilica. Modeli su bili izrađeni od gipsa (Galiplaster - tip 2, Galenika) i tvrdog gipsa (Gipsogal - tip 3, Galenika) u odnosu 1:1 - odnosi praha gipsa 0,5:0,5:1 (1 deo vode), posle uzimanja anatomskog preliminarnog otiska bezubih vilica alginatom (Alginogal, Galenika) u standardnoj metalnoj kašici (Slike la i 1b).

Uz površine gipsa na 139 parova modela vilica adaptirane su aluminijumske folije debljine $0,5 \mathrm{~mm}$ (Slike 1c i 1d). Folije su postavljene na milimetarsku hartiju radi merenja površina (Slike 2a i 2b). Svaka folija je zatim uklonjena, kako bi se izmerio broj kvadrata i površina koju je folija zauzimala na milimetarskom papiru (Slike 3a i 3b).
Sekundarno, zbog provere, površine su izmerene i pomoću mehaničkog planimetra (G. Coradi, Zürich, Switzerland, serial no. 49823) (Slika 4). Greška pri merenju je bila $1 \%$. Skeletna klasa bezubih vilica je utvrđena na osnovu profilnih cefalometrijskih radiograma glave i analize ugla ANB (SNA-SNB) (Slike 5 i 6).

\section{REZULTATI}

Površine bezubih gornjih vilica bile su $4654 \pm 407 \mathrm{~mm}^{2}$ kod muškaraca i $4212 \pm 368 \mathrm{~mm}^{2}$ kod žena (Slika 7), a razlika je bila statistički značajna $(\mathrm{p}<0,001)$. Površine bezubih donjih vilica bile su $2843 \pm 339 \mathrm{~mm}^{2}$ kod muškaraca i $2334 \pm 295 \mathrm{~mm}^{2} \mathrm{kod}$ žena (Slika 8); i ova razlika je bila statistički značajna $(p<0,001)$. Razlike su uočene i pri poređenju dimenzija donjih i gornjih bezubih vilica $(\mathrm{p}<0.001)$. Izmerene vrednosti uglova ANB su bile 2-4 stepena.

\section{DISKUSIJA}

Preliminarni anatomski modeli bezubih gornjih i donjih vilica su obavezno i rutinski prihvaćeno sredstvo u analizi terapije i postupka izrade totalne proteze [1-5]. Ovaj model bezube vilice je prvi model koji se može koristiti i u analizi oblika, dimenzija i površine budućih nosećih tkiva bezube vilice pre postavljanja totalne proteze, a i u kasnijim postupcima (izrade individualne kašike) u izradi totalne proteze, $\mathrm{u}$ analizama modela vilica zbog postavljanja implantata ili u preprotetičkoj hirurgiji za modifikaciju oblika bezubog grebena radi uspešnog postavljanja i stabilizacije proteze $[10,11]$.

U stručnoj literaturi nema mnogo podataka o merenju površine bezubih vilica bez obzira na činjenicu da je podatak o površini od ogromnog značaja ne samo zbog bezuslovne i značajne povezanosti bolje retencije i stabilnosti totalne proteze s 
većom površinom nosećih tkiva, već i zbog planiranja u preprotetičkoj i rekonstruktivnoj hirurgiji vilica. Dosad je opisano samo nekoliko metoda u merenju površine vilica: metoda replikacije s primenom empirijske formule u izračunavanju površine nosećih tkiva, planimetrijska metoda merenja površine, žičani model s analizom napona primenom metode konačnih elemenata i trodimenzionalni virtuelni model vilice s mogućnošću analize izabrane površine modela bezube vilice [12-15]. Planimetrijska metoda se može smatrati najjednostavnijom i najprihvatljivijom u svakodnevnoj praksi, pri čemu treba istaći da je metoda sasvim precizna i sa beznačajnom greškom pri merenju $[13,16]$.

Pored prevashodnog i prioritetnog sagledavanja oblika, veličine, reljefnosti, odnosno konfiguracije nosećih tkiva otisnutih na modelu, preliminaran model pruža podatak i o tome na kojoj površini nosećih tkiva će biti izrađena zubna nadoknada. Površina nosećih tkiva ukazuje na dva važna činioca: na to da li i u kojoj meri postoji resorpcija tkiva, te kolika je raspoloživa površina koja će kasnije biti opterećena bazom totalne proteze. S obzirom na to da je totalna proteza čvrsto telo naslonjeno na površinu nosećih tkiva, od veličine površine tkiva će zavisiti i stabilnost proteze. Ukoliko će površina naslanjanja proteze biti većih dimenzija, proteza će biti stabilnija. Suprotno, ukoliko je površina na koju će proteza biti naslonjena manjih dimenzija - proteza neće biti stabilna. Stoga je procena realne dimenzije površine nosećih tkiva, pored visine i dužine bezubih vilica, izuzetno važan parametar pri sagledavanju stanja nosećih tkiva od kojeg će zavisiti i stabilnost proteze $[6,9,11,16]$.

Skeletni odnosi vilica su determinisan parametar koji ostaje očuvan i posle ekstrakcije poslednjeg zuba iz vilica $[6,7,8]$. $\mathrm{U}$ tom smislu je posebno važno poznavati skeletni odnos kod pacijenta bez zuba, kako se eventualna odstupanja ili razlike u dimenziji vilice ne bi pripisali procesu resorpcije, umesto smanjenoj veličini vilice kod pacijenata sa skeletnom klasom II, ili povećanoj veličini vilice kod pacijenata sa skeletnom klasom III [6]. U ovom istraživanju je ispitana velika grupa pacijenata s najčešćim skeletnim odnosom vilica klase I. Bez obzira na to što su u ovom istraživanju utvrđene razlike u dimenzijama u pogledu smanjenja veličine i površine bezube vilice, ipak bi se na osnovu rezultata studije moglo tvrditi da je i kod pacijenata bez zuba sa skeletnom klasom I odnos vilica u istoj ravni u prostoru s manje ili više izraženim odstupanjima u površinama bezubih vilica.

Na kakvom modelu treba da bude obavljena analiza površina? Iz svakodnevne prakse je poznato da model bezube vilice može biti izliven na osnovu preliminarnog (anatomskog) otiska bezube vilice alginatom u standardnoj metalnoj kašici, kao i na osnovu funkcionalnog otiska bezube vilice cink-oksid eugenol pastom u individualnoj kašici $[1-5,10]$. Samim tim može postojati nedoumica da li je analizu površina potrebno uraditi na konačnim radnim modelima izrađenim od tvrdog gipsa ili je dovoljno analizu obaviti na preliminarnom modelu. Budući da se na radnom modelu od tvrdog gipsa precizno uočavaju razlike između graničnih tkiva, slobodne (pokretne) i nepokretne sluzokože, kao i fino i precizno reprodukovane površine svih anatomskih detalja izlivenih od tvrdog gipsa, čini se da analizu površina treba obaviti na radnom modelu od tvrdog gipsa. Ipak, s obzirom na zadovoljavajući stepen reprodukcije nosećih tkiva na preliminarnom, studijskom modelu i na to da se granica pokretne i nepokretne sluzokože jasno raspoznaje i na preliminarnom modelu, analiza površina se može uspešno obaviti već na preliminarnom modelu, što su pokazali i rezultati našeg istraživanja. Pored toga, analiza na preliminarnom, studijskom modelu jeste postupak koji se na rutinski način može primeniti na početku preprotetičkog rekonstruktivno-hirurškog zahvata na bezuboj vilici.

\section{ZAKLJUČAK}

Površina je važan parametar $\mathrm{u}$ analizi i proceni nosećih tkiva bezube vilice. Izmerene površine bezubih gornjih vilica su bile veće kod muškaraca nego kod žena. Bezube površine na desnoj strani nisu bile potpuno simetrične bezubim površinama na levoj strani.

\section{NAPOMENA}

Rad je saopšten na 50. Kongresu Antropološkog društva Srbije s međunarodnim učešćem, koji je održan 1-4. juna 2011. godine u Jagodini. 